\section{Zellkern und Zellzyklen}

Zellkern und Zellzyklen. By Walter Nagl. Pp. 486. (Eugen Ulmer: Stuttgart, 1977.) DM120.

THE literal translation of the German title of this book would be "Cell nucleus and cell cycles". However, in my opinion this is far too modest a title considering the book's scope. A short glimpse at the table of contents convinces the reader that the book has a much broader outlook and deals with such fundamental problems as molecular, structural and functional organisation of the cell nucleus and chromatin; DNA replication, mitotic and various modified cell cycles; and the role of the cell nucleus, nucleo-cytoplasmic interactions and cell cycles in development and differentiation of multicellular organisms. All these topics are covered from a development biologist's point of view. The author is a well known cell biologist who originally carried out research in plant cytology and discovered the polytenic chromosomes in the suspensor cells of the plant Phaseolus coccineus in the early sixties. At this time it was still fashionable for cytologists as well as for cell biologists, trained either in botanical or zoological sciences, to have only a very limited mutual exchange of ideas. Nagl was certainly one of the few 'botanists' who realised very early that such historical and in many respects artificial boundaries between such disciplines had to be transgressed in order to solve the fundamental and really important problems in biology.

The book is part of a series entitled "Phytology-Classical and Modern Botany Represented by Individual Scientists". One can pose the question as to whether the author possibly succumbed somewhat to the concept of this series. I found that the botanical cell and molecular biology is treated very comprehensively but that important results and concepts derived from molecular biology of zoological or human cell material are either not discussed or only incompletely. Although $\mathrm{Nagl}$ proves to have an extremely broad knowledge of botanical and zoological developmental biology, I feel that it is impossible for any single scientist to cover the whole field of molecular and cellular developmental biology of plants, animals and humans really authoritatively.

The author, however, has done an immense job, considering that nearly 4,000 papers are cited in the book. This naturally makes it an excellent reference book, especially for someone who lacks an extensive knowledge of either plant or animal cell and molecular biology. On the other hand, so many citations create difficultics not only for the writer but also for the reader. Personally, I often missed the emphasis on important and fundamental facts and a critical evaluation of different and/or conflicting experimental results and interpretations, and for this reason I would not recommend the book as a textbook for undergraduate students.

The book contains not only experimental results but also gives a full description of many experimental techniques used in cell and molecular biology, for example, DNA, RNA and chromatin isolation. Since only standard techniques are presented, the reader should bear in mind that generally such techniques have to be modified and adapted for different animal and plant species. The many informative tables which summarise data on cell and molecular biology from a large number of plant and animal species deserve special attention.

\section{Individual differences in human memory}

Human Memory: Theory, Research and Individual Difference. By Michael W. Eysenck. Pp. 366. (Pergamon: Oxford and New York, 1977.) £8.

HUMAN MEMORY has been a popular topic for books in recent years; some are general texts, at elementary or advanced levels; some concentrate on special areas; and some are monographs on recent research. This particular book has elements of both the latter classes. The core of the work is formed by the author's own studies of individual differences in memory; these are fleshed out by chapters reviewing each of the areas of memory closest to those studies. There is a notable concentration on the most recent and little-known findings; references to 1977 are common; and quite a few of the experiments cited are still unpublished. As a result, these general review chapters are likely to be useful and suggestive reading for research workers active in topics such as the use of imagery, retrieval mechanisms, or sentence memory. They will find much that is new to them. Conversely, some of the experiments quoted from other workers may be hard to replicate, and many promising ideas are still untested. Because of this, because the relative absence of old-established findings or those from other approaches to memory, and because there are rather few links between the particular fields of research, one would scarcely advise this book as a general textbook. Specialists, however, ought to read it and will probably find particular sections that they will want their students to read.

The main glory of the book is the emphasis on differences between people. That topic is long neglected by experi-
We all know that progress in cell and molecular developmental biology has been extremely rapid in recent years, accompanied by an ever-increasing number of publications. The author has only cited literature up to autumn 1975, and it is therefore understandable that important new results and interpretations, for example, on chromatin structure, DNA sequencing or recombinant DNA research, are not discussed. In summary, I consider Nagl's book as a very valuable source of reference for any scientist who is interested in the structure and function of the cell nucleus, chromatin and DNA from a developmental biologist's point of view.

Heinz Tobler

Heinz Tobler is Professor of Zoology and Director of the Institute of Zoology at the University of Freiburg, Switzerland.

mentalists despite the reminders of its importance which are to be found in the raw data of every study. The particular line taken by this author is to review the evidence for changes in memory produced by temporary changes in the state of arousal, to regard the degree of introversion or neuroticism of the individual as resulting in chronic differences in arousal, and then to examine differences in memory between people differing on the personality dimensions. The hope is to find evidence of changes like those produced by arousal within an individual, and a number of encouraging results are indeed reported. There are also brief accounts of the effects of ageing, of "field dependence", of intelligence, and other similar factors. Given the general neglect of individual differences, however, the main focus is on the implications for memory of the two major dimensions of personality.

As those in the area will know, there are severe problems in linking arousal too simply to those dimensions. The formulations of Gray, of Pribram, or of other authors are quite different from those of the older Eysenck, and are not given detailed analysis here.

One can well accept the experiments of the son, and indeed the two-dimensional data of the father, without accepting the theoretical structure of the latter. Many of us therefore will welcome the revival of individual differences in memory, will feel that every research worker in the field should read the findings in this book or in the author's earlier papers; and yet feel the need to link those results to a different class of theory. Meanwhile, the results themselves are a worthy step forward.

Donald E. Broadbent

Donald E. Broadbent is an MRC staff member in the Department of Experimental Psychology at the University of Oxford, UK. 